\title{
Penetration of $M$ cells and destruction of Peyer's patches by Yersinia enterocolitica: an ultrastructural and histological study
}

\author{
INGO B. AUTENRIETH and RUTH FIRSCHING
}

Institut für Hygiene und Mikrobiologie der Universität Würzburg, Josef-Schneider-Strasse 2, D-97080 Würzburg, Germany

\begin{abstract}
Yersinia enterocolitica is enteropathogenic for man and rodents. Previous studies provided evidence that $Y$. enterocolitica invades the lymphoid follicles of the Peyer's patches (PP) of the small intestine. In this study $Y$. enterocolitica-induced tissue alterations of the follicle-associated epithelium (FAE) and the underlying PP tissue were analysed by scanning (SEM) and transmission electron microscopy (TEM) as well as by conventional histological examination. For this purpose, an experimental mouse infection model including orogastric infections as well as ileal loop experiments were used. A rapid and selective colonisation of the FAE after orogastric yersinia infection was observed by SEM. TEM studies confirmed that $Y$. enterocolitica adhered closely to the FAE including $M$ cells and enterocytes. Histological studies and TEM revealed that $Y$. enterocolitica selectively invaded the PP via $M$ cells but not via other cells of the FAE. One day after $Y$. enterocolitica infection the FAE was altered and small micro-abscesses comprising yersiniae expressing the major outer-membrane protein YadA were observed immediately beneath the FAE. Adjacent villi were dilated from lymphangiectasis and transmigrating polymorphonuclear leucocytes (PMNL) were found within the epithelium. At 5-7 days after infection the FAE and parts of PP were destroyed. Profound alterations of the cyto-architecture of the PP were due to the enormous recruitment of PMNL. By day 5 after infection, abscesses were found in the mesenteric lymph nodes. However, TEM studies revealed evidence that $Y$. enterocolitica may disseminate from the PP not only via the lymphatics but also by invasion of blood vessels. Taken together, the results of this study demonstrate that the FAE is the primary site of host-pathogen interaction in $Y$. enterocolitica infection and that this pathogen penetrates $M$ cells and subsequently induces destruction of the PP.
\end{abstract}

\section{Introduction}

Yersinia enterocolitica is a frequent cause of bacterial enteritis and enterocolitis in man $[1,2]$. Moreover, mesenteric lymphadenitis as well as systemic infections that subsequently lead to abscess formation in liver and spleen can occur $[1,3,4]$. Furthermore, immunopathological sequelae such as reactive arthritis are associated with intestinal $Y$. enterocolitica infection $[1,5]$. In the latter cases, chronic persistent infections including high serum levels of yersinia-specific $\operatorname{IgA}$ antibodies are commonly found [6]. Because $Y$. enterocolitica is enteropathogenic for rodents, animal models have been established to elucidate the pathogenesis of yersiniosis $[7,8]$. The experimental mouse infection model is of major clinical relevance as yersiniosis in mice closely resembles human yersinia infections $[9,10]$. Previous

Received 5 June 1995; revised version accepted 16 Aug. 1995.

Corresponding author: Dr I. B. Autenrieth. studies indicated that $Y$. enterocolitica causes abscesses and production of interleukin-1 in lymphoid follicles of Peyer's patches (PP) of the small intestine [7,11]. The latter are a part of the gut-associated lymphoid tissue (GALT) $[12,13]$. From there, yersiniae disseminate to mesenteric lymph nodes (MLN), spleen, liver and lungs $[7,10]$. At this phase of the infection T-cell-dependent immune responses are involved in the protective host response against this pathogen $[10,14-16]$.

While yersinia-induced tissue alterations and host responses in the spleen and liver have been characterised extensively, the events occurring in PP during the early phase of the infection have rarely been addressed. Previous studies provided evidence that PP, including $M$ cells, may be involved in intestinal invasion by $Y$. enterocolitica $[17,18]$. $M$ cells are a part of the follicle-associated epithelium (FAE) and specialise in the delivery of antigenic particles from the lumen of the gut to the lymphoid follicles of the PP [19-21]. However, most of the studies addressing the invasiveness of yersiniae have 
been performed in vitro with HeLa or HEp-2 cells. These studies revealed that $Y$. enterocolitica can penetrate certain cell lines and that this process depends on two genes (inv, invasin; and ail, attachment and invasion locus) which encode for proteins that mediate bacterial invasiveness $[22,23]$. However, the significance of these findings is not yet clear [24].

In contrast to $Y$. enterocolitica, the pathomechanisms and host responses to intestinal Salmonella typhimurium infection have been studied in more detail [2528]. A recent electron microscopic study demonstrated that $M$ cells are obviously the primary site of interaction between $S$. typhimurium and the host [25]. Hence, this intestinal pathogen first penetrates and then destroys $M$ cells of the PP [25]. The events occuring during this initial interaction may be important for the subsequent infection process. Likewise, Shigella flexneri enters M cells and then kills adjacent macrophages, possibly by induction of apoptosis [29]. Moreover, transmigrating polymorphonuclear leucocytes (PMNL) may aggravate the infection process in shigellosis [30].

Whether comparable pathomechanisms may be involved in yersiniosis has not yet been investigated in detail. Therefore, the present study aimed to follow the events operating in the early phase of $Y$. enterocolitica infection in the PP of experimentally infected mice and to characterise the yersinia-induced tissue alterations of the PP by electron microscopy as well as conventional histology.

\section{Materials and methods}

\section{Mice}

Female 6-8-week-old BALB/c mice were purchased from Charles River Wiga (Sulzfeld) and kept in positive pressure cabinets under specific pathogen-free conditions. Mice were provided with food and water $a d$ libitum.

\section{Bacteria and infection of animals}

Plasmid-harbouring $Y$. enterocolitica strain WA-314 of serotype $\mathrm{O} 8$ [31] was grown at $28^{\circ} \mathrm{C}$ as described previously [14]. Before infection the bacteria were washed three times with phosphate-buffered saline (PBS), $\mathrm{pH} 7.4$, containing bovine serum albumin $0.5 \%$ and adjusted to the desired concentration. Before each experiment, mice were starved for $18 \mathrm{~h}$ to clear the contents of the bowel. Mice were infected either orogastrically by administering $200 \mu \mathrm{l}$ of a bacterial suspension containing $10^{9}-10^{10}$ viable bacteria with a gastric tube or by direct injection of the bacteria into a ligated or non-ligated ileal loop. In the latter case, mice were anaesthetised before surgery by intraperitoneal administration of $3 \mathrm{mg}$ of pentobarbital (Rhone Merieux, Laupheim, Germany). When mice were under anaesthesia an incision was made through the abdominal wall and two ligations of a segment of the ileum containing at least two PP were performed. Then, $10^{9}-$ $10^{10}$ bacteria were injected directly into the intestinal lumen and the abdominal wall was closed. The mice were kept under anaesthesia for $1-3 \mathrm{~h}$ before they were killed. The number of bacteria injected was determined for each experiment by plating $200 \mu l$ of serial dilutions of the injected bacterial suspension on Mueller Hinton agar and counting after incubation for $48 \mathrm{~h}$. In the experiments lasting for several days, mice were starved after the injection for a further $4 \mathrm{~h}$ and then kept in cages with grid bottoms to avoid reinfection by coprophagy.

\section{Histology and immunohistology}

Peyer's patches and mesenteric lymph nodes were excised and fixed immediately in buffered paraformaldehyde (Merck, Darmstadt, Germany) 2\%, pH 7.4, at $4^{\circ} \mathrm{C}$ for $3-4 \mathrm{~h}$. Then the samples were incubated in PBS containing saccharose $6.8 \%$ for $16 \mathrm{~h}$ at $4^{\circ} \mathrm{C}$ followed by incubation in acetone (Merck) for $1 \mathrm{~h}$ at $4^{\circ} \mathrm{C}$ to dehydrate the tissue. Finally, tissues were infiltrated for $6 \mathrm{~h}$ at $4^{\circ} \mathrm{C}$ and then embedded in glycolmethacrylate containing Technovit 8100 (Heraeus Kulzer, Wehrheim, Germany) and kept on ice for $3 \mathrm{~h}$ during polymerisation according to the manufacturers' instructions. Embedded tissues were kept at $-80^{\circ} \mathrm{C}$ until further use. For immunohistology, 1- $\mu \mathrm{m}$ thick sections were cut on a 2065 supercut microtome (Reichert Jung, Nußloch, Austria). The sections were digested for $10 \mathrm{~min}$ with a solution containing trypsin (Sigma) $0.01 \%$ and calcium chloride $0.1 \%$, pH 7.8. After washing steps, sections were incubated with polyclonal rabbit anti-yersinia antibodies (WA-v) or rabbit antiyersinia outer-membrane protein YadA [32] diluted 1 in 100 in PBS containing sheep serum $20 \%$ for $2 \mathrm{~h}$ at $37^{\circ} \mathrm{C}$. Then slides were washed and endogenous peroxidase was blocked by PBS containing Perhydrol (Merck) $0.06 \%$. This was followed by washing and incubation with peroxidase-conjugated goat anti-rabbit antibodies (Dianova, Hamburg, Germany) diluted 1 in 50 in PBS containing sheep serum $20 \%$ for $30 \mathrm{~min}$ at room temperature. The signal was developed with 3,3 diaminobenzidine-tetra-hydrochloride (Serva, Heidelberg, Germany). Finally, sections were counterstained with Mayer's haemalum (Merck) and mounted in Entellan (Merck). Alternatively, tissues were snap frozen and embedded in OCT Tissue Tek compound (Nunc, Roskilde, Denmark). Cryosections were performed and stained with anti-yersinia WA-v or antiMac-1 (complement $\mathrm{C} 3 \mathrm{~b}$ receptor, $\mathrm{CD} 11 \mathrm{~b} / \mathrm{CD} 18$; clone M1/70) including PAP- and APAAP-methods as described recently [10].

\section{Scanning electron microscopy (SEM)}

The gut was cut longitudinally and washed gently with PBS, pinned flat and fixed for $18 \mathrm{~h}$ in ice-cold 
glutardialdehyde (Roth, Karlsruhe, Germany) $6.25 \%$ in Sörensen's Na-K phosphate buffer, $\mathrm{pH} 7.4$, at $4^{\circ} \mathrm{C}$. After washing five times with Sörensen's buffer, the tissues were dehydrated through a graded series of acetone, critical point dried with a critical point dryer (CPD 030; BAL-TEC, Walluf, Germany) and coated with a 30-nm thick gold layer with a sputter coater (SCD 005; BAL-TEC). The samples were examined with a Zeiss scanning electron microscope DSM 962 (Zeiss, Oberkochen, Germany) at $15 \mathrm{kV}$.

\section{Transmission electron microscopy (TEM)}

The gut was cut longitudinally and the PP were excised, cut and divided into two pieces and incubated immediately in half-concentrated Karnovsky's solution consisting of a paraformaldehyde $2 \% \mathrm{w} / \mathrm{v}$, glutardialdehyde $2.5 \% \mathrm{v} / \mathrm{v}$ and dimethyl sulphoxide (Sigma) $1 \%$ in cacodylate buffer, $\mathrm{pH} 7.5$, at $4^{\circ} \mathrm{C}$ for $16 \mathrm{~h}$ as described elsewhere [33]. After washing steps, the samples were post-fixed with osmium tetroxide (Electron Microscopy Sciences, Washington, DC) $2 \%, 0.1 \mathrm{M}$ cacodylate buffer and ruthenium red (Merck) for $5 \mathrm{~h}$ at $4^{\circ} \mathrm{C}$. After washing with de-ionised water the samples were stained with uranyl acetate (Merck) $0.5 \%$ at $4^{\circ} \mathrm{C}$ for $16 \mathrm{~h}$, followed by incubation in de-ionised water, dehydration in serial graded ethanol and infiltration and embedding with Epon 812 (Serva, Heidelberg, Germany); polymerisation was at $60^{\circ} \mathrm{C}$ for $48 \mathrm{~h}$. Semi-thin sections $(1 \mu \mathrm{m})$ were cut and stained with methylene blue (Merck) to localise PP. Then ultrathin sections (60-90 nm) were cut and stained with alcoholic uranyl acetate and lead citrate (Fluka, Buchs, Switzerland). Finally, the samples were examined with a Zeiss EM 900 transmission electron microscopy at $80 \mathrm{kV}$.

\section{Results}

\section{Ultrastructure of PP from BALB/c mice}

Between 5 and 10 PP were found macroscopically in the normal small intestine of non-infected BALB/c mice. By SEM, 3-10 domes which were characterised by the FAE could be observed on the luminal surface of each PP (Fig. 1a). The FAE was smooth (Fig. 1b) and comprised enterocytes, few goblet cells and $c .10 \%$ $M$ cells as described previously $[12,13]$. The $M$ cells could be identified easily by their short microvilli (Fig. 1c) and by their large number of vacuoles seen by TEM. On the surface of the FAE and the villi, segmented filamentous bacteria (SFB) which are part of the normal intestinal flora of mice and rats $[34,35]$ were found frequently (not shown).

\section{Early alterations of FAE and villi induced by Y. enterocolitica}

To characterise the early events during invasion of the intestine by $Y$. enterocolitica, BALB/c mice were

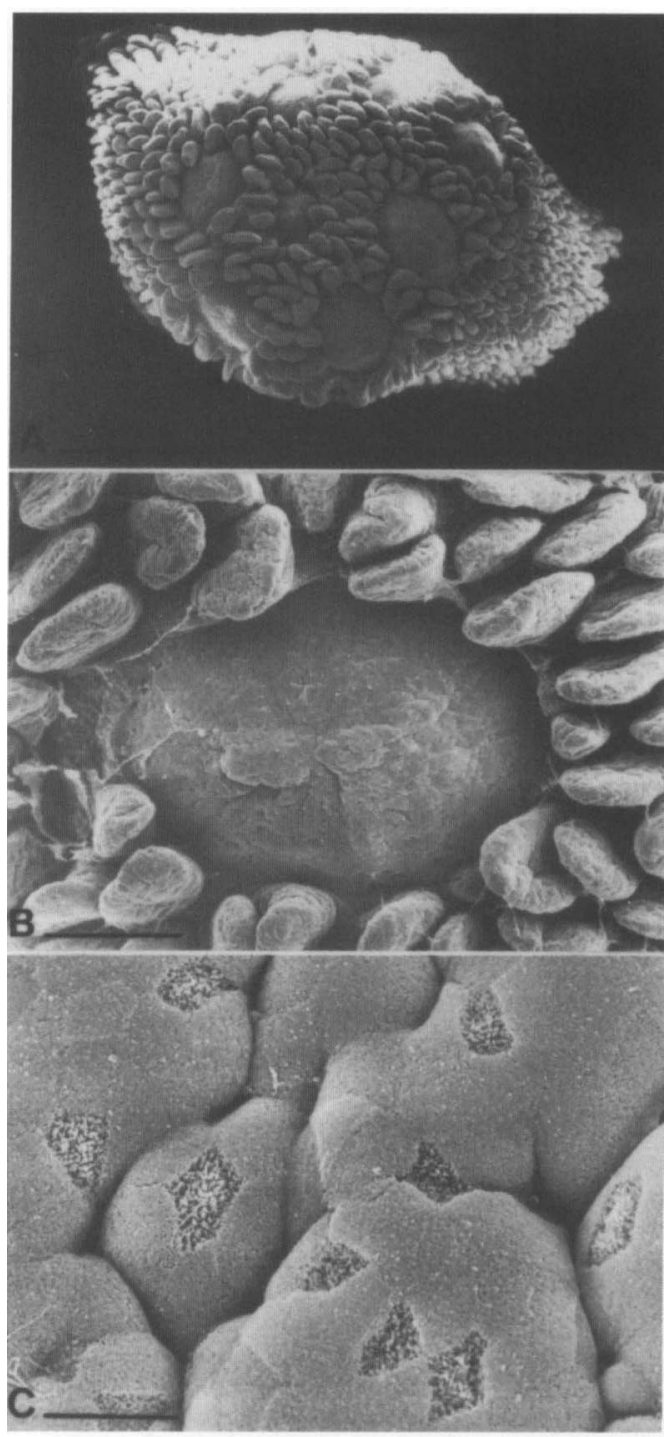

Fig. 1. SEM of the luminal surface of normal uninfected $P P$ of the small intestine of BALB/c mice. A, seven domes with adjacent villi, bar $=1 \mathrm{~mm} ; B$, dome area, bar $=200 \mu \mathrm{m} ; \mathrm{C}$, FAE consisting of enterocytes and $M$ cells, bar $=10 \mu \mathrm{m}$.

infected orogastrically with $10^{9}-10^{10} \mathrm{cfu}$ of virulent $Y$. enterocolitica WA-314 of serotype O8. At $24-48 \mathrm{~h}$ after infection the FAE of both the domes and the adjacent villi appeared altered. Many vesicles or bubble-like structures on the surface of the FAE including $M$ cells (Fig. 2) and villi adjacent to PP were found. Two days after infection SFB could no longer be observed on the FAE and adjacent villi. Furthermore, the domes of the PP appeared to be flattened or even retracted and the surface of the FAE was rough (Fig. 3a, b). By higher magnifications, bacteria attached to the FAE could be recognised (Fig. 3c). Moreover, remnants of cells which might be nuclei were observed on the FAE suggesting that epithelial cells had been damaged (Fig. 3c). The villi adjacent to the FAE were slightly enlarged from $80 \mu \mathrm{m}$ diameter to more than $100 \mu \mathrm{m}$ and distorted (Fig. 4). However, there was no evidence for disintegration of 


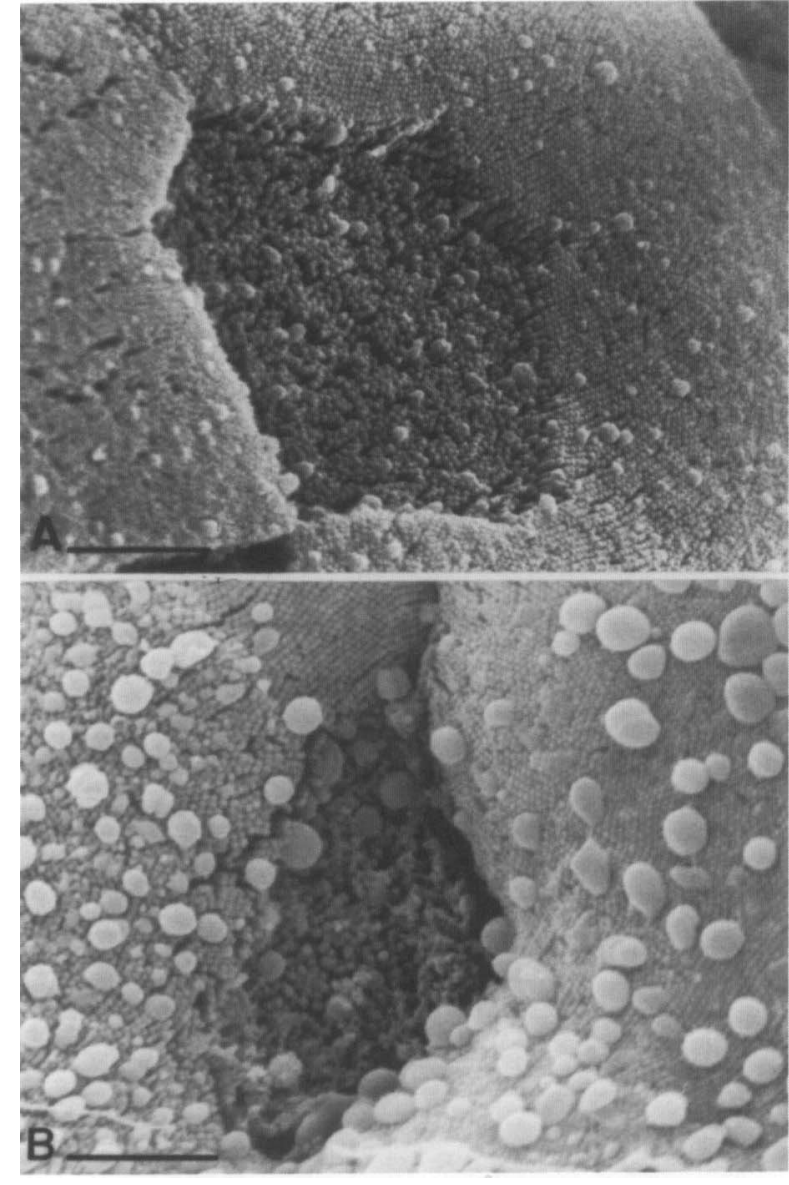

Fig. 2. SEM of $M$ cell within the FAE. A, Normal, uninfected mice, bar $=2 \mu \mathrm{m} ; \mathrm{B}, 24 \mathrm{~h}$ after orogastric infection with $10^{10} \mathrm{Y}$. enterocolitica, many bubble like structures/vesicles on the surface, bar $=2 \mu \mathrm{m}$.

the epithelial cell layer of the villi. Moreover, in contrast to the FAE no yersiniae were observed attached to the epithelium of the villi.

\section{Penetration of $M$ cells by $Y$. enterocolitica}

As the sampling error of investigations of PP from orogastrically infected mice is quite considerable, the TEM studies addressing the invasion of the FAE by $Y$. enterocolitica were performed with PP tissues obtained from ileal loop experiments. For this purpose $10^{9}-10^{10}$ cfu of $Y$. enterocolitica were injected directly into ligated or non-ligated ileal loops of mice. At various intervals after the infection mice were killed and the PP were excised and prepared for TEM examination. $Y$. enterocolitica were found to be closely attached to cells of the FAE, including enterocytes and $M$ cells (Fig. 5) $30 \mathrm{~min}$ after infection. However, there was no evidence for invasion of enterocytes by $Y$. enterocolitica. In contrast, yersiniae could be detected within $M$ cells by $1 \mathrm{~h}$ after the infection (Fig. 6). In the $M$ cells $Y$. enterocolitica was located within vacuoles. Despite the high numbers of bacteria administered, this event was observed only very rarely. Nonetheless, these results suggest that $Y$. enterocolitica does not adhere to

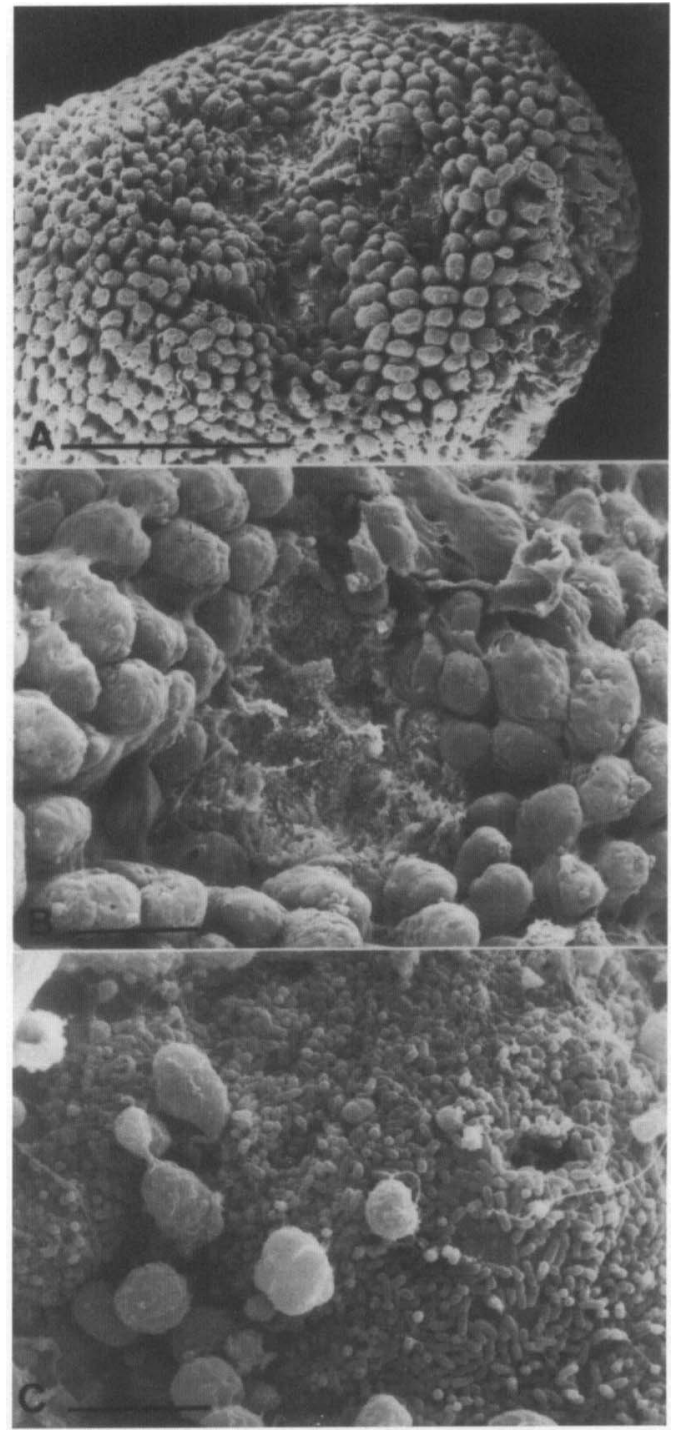

Fig. 3. SEM of the luminal, surface of $P P 48 \mathrm{~h}$ after orogastric infection with $10^{10} Y$. enterocolitica. A, PP with domes, bar $=1 \mathrm{~mm}$; B, alteration of the luminal surface of a dome and adjacent villi, bar $=200 \mu \mathrm{m}$; C, FAE with bacteria and remnants (possibly nuclei) of cells, enterocytes and $M$ cells cannot be identified, bar $=10 \mu \mathrm{m}$.

villi but preferentially and unselectively adheres to different cell types of the FAE. However, invasion of the intestinal wall occurs, probably selectively by penetration of $M$ cells. Nevertheless, due to the sampling error of the methods used, an alternative mode of invasion cannot be excluded.

\section{Yersinia-induced micro-abscesses in PP}

Histological examination of the whole intestine of infected mice revealed that only PP and no other structures were involved in the infection. However, not all PP were infected after orogastric administration of $Y$. enterocolitica. Hence, only $c$. $30-50 \%$ of the PP appeared to be involved. At $24 \mathrm{~h}$ after orogastric infection, small micro-abscesses were found in the dome area of these PP (Fig. 7). Practically all yersiniae 


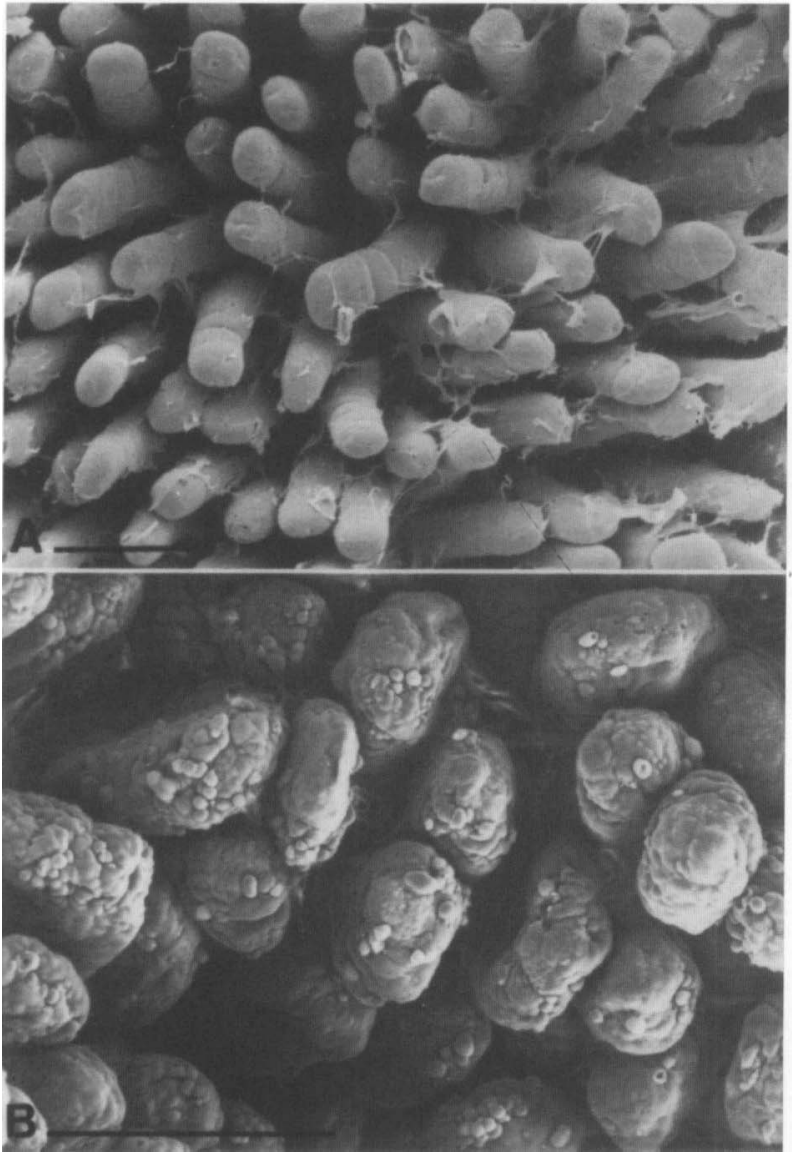

Fig. 4. SEM of villi adjacent to PP: A, from a normal uninfected mouse; $\mathbf{B}, 72 \mathrm{~h}$ after orogastric infection with $10^{10} \mathrm{cfu}$ of $Y$. enterocolitica. Bubble-like structures/ vesicles on the surface of the enlarged villi, bar $=200 \mu \mathrm{m}$.

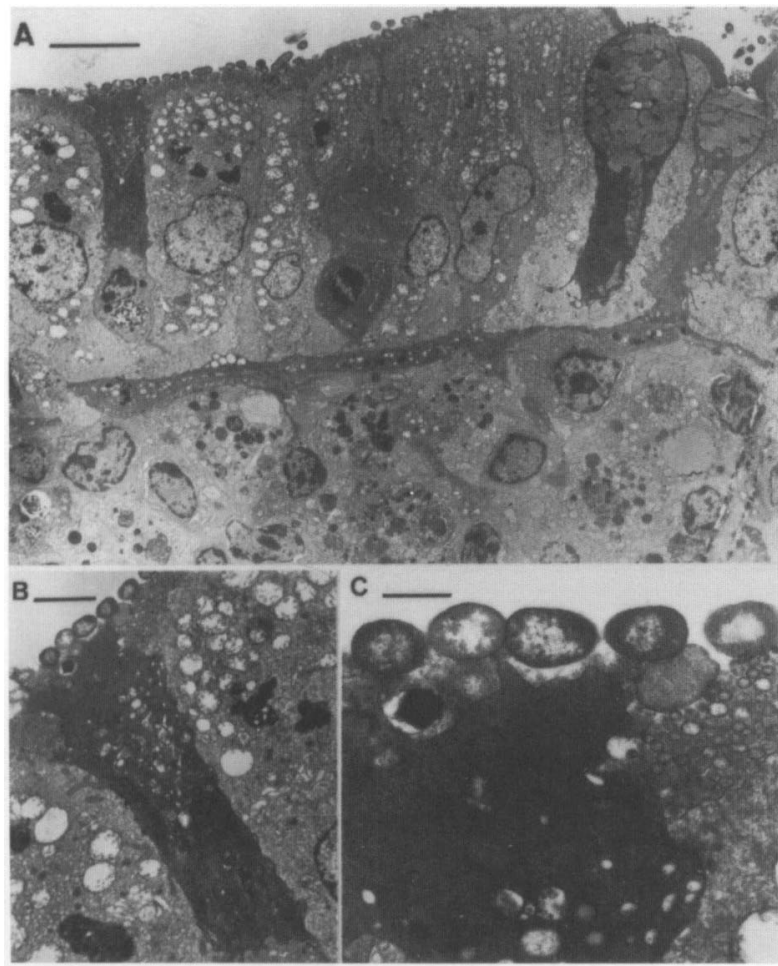

Fig. 5. TEM of $Y$. enterocolitica closely attached to the FAE $30 \mathrm{~min}$ after infection of an ileal loop. Bars: A, 20; B, $5 ; \mathbf{C}, 1 \mu \mathrm{m}$

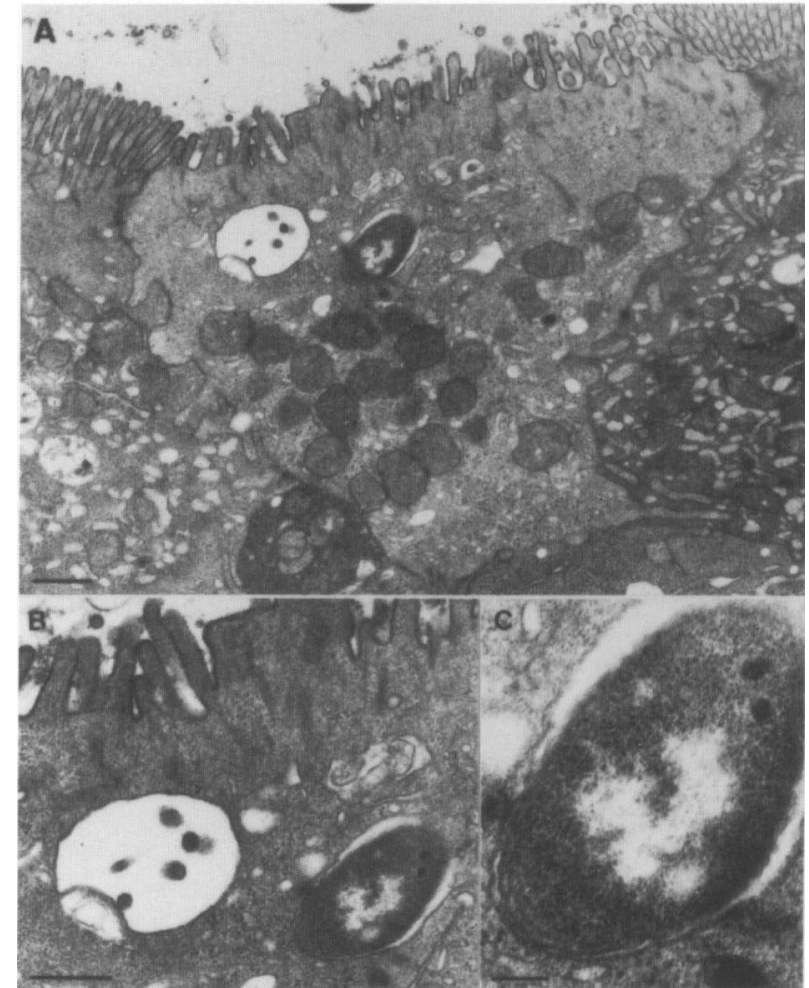

Fig. 6. TEM of $Y$. enterocolitica within a vacuole of a $M$ cell $60 \mathrm{~min}$ after infection of an ileal loop. Microvilli of the $M$ cell are shorter and thicker than those of the adjacent enterocytes. Bars: A, 5; B, 1; C, $0.25 \mu \mathrm{m}$.

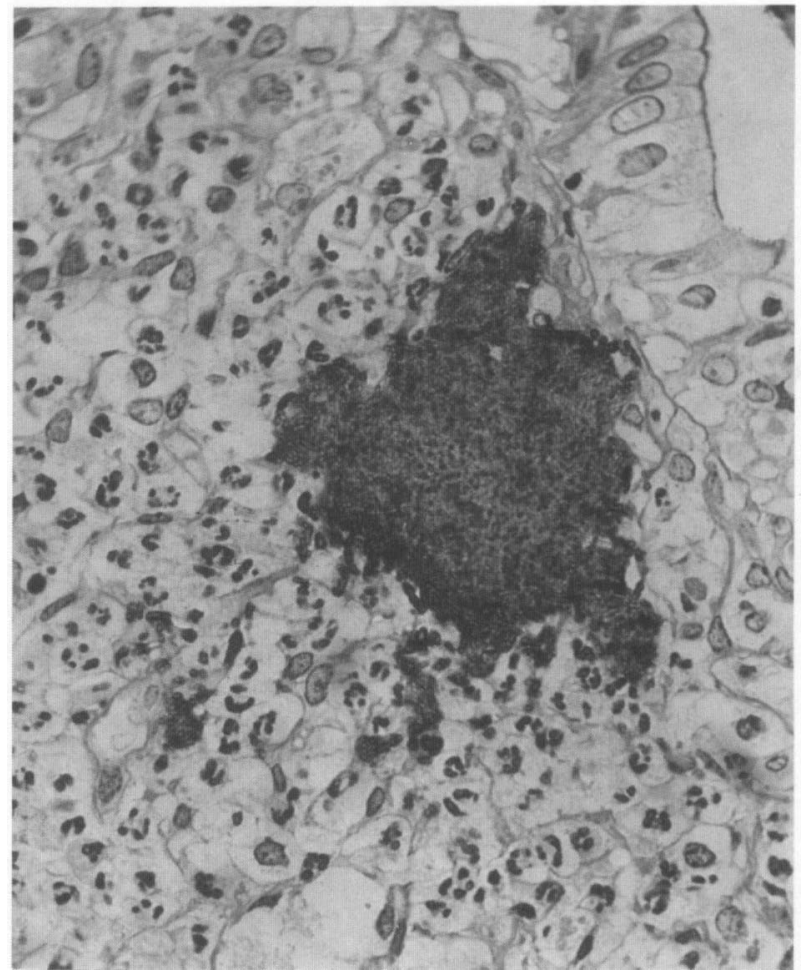

Fig. 7. Light microscopy (semi-thin section) of PP from a BALB/c mouse $24 \mathrm{~h}$ after orogastric $Y$. enterocolitica infection. Immunostaining (PAP method, brown signal) with polyclonal anti-yersinia antibodies (WA-v). Microabscess comprising extracellularly located yersiniae and PMNLs. 
expressed YadA and were located extracellularly in PP tissue, and PMNLs were recruited into these lesions (Fig. 7). Moreover, an increased number of apoptotic cells and apoptotic bodies within phagocytic cells was observed around abscesses as well as in the germ centres of the lymphoid follicles of the PP (not shown). At 2-4 days after infection, oedematous enlarged villi adjacent to infected PP could be observed. The lymphatics within these villi were dilated and contained high numbers of cells which were predominantly lymphocytes as a sign of lymphangiectasis (Fig. 8a) while purulent lymphangitis was not observed. Moreover, an increased number of PMNLs was found in the villi adjacent to inflamed PP. Some of these cells were observed within the epithelium, suggesting that these cells transmigrate the epithelial barrier of the villi (Fig.
$8 b)$. However, this phenomenon was observed only on that side of the villi which was attached to the PP.

\section{Destruction of PP by $Y$. enterocolitica}

At day 7 after infection the cytoarchitecture of the infected PP was almost completely destroyed and yersinia-induced abscesses often replaced the lymphoid follicles entirely (Fig. 9). SEM studies on these tissues likewise demonstrated enlarged villi adjacent to the infected PP and destruction of the FAE (Fig. 10a). On the luminal surface of the remnants of the FAE many phagocytes and yersinia bacilli were observed (Fig. 10b). The latter showed chain formation, which is believed to result from the expression of plasmidencoded virulence factors such as YadA. Intact FAE
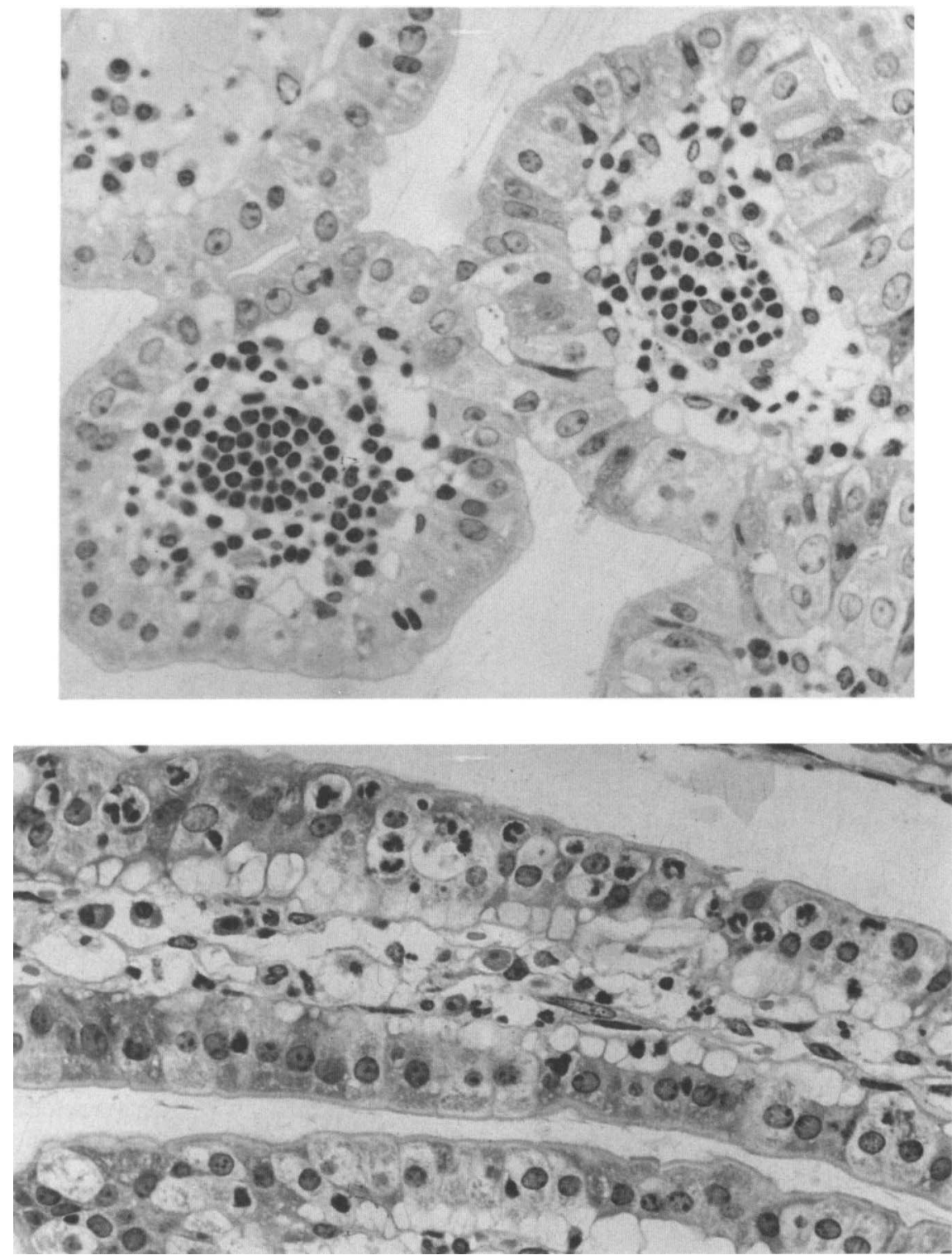

Fig. 8. Light microscopy (semi-thin section) of villi adjacent to yersinia-infected PP 4 days after orogastric infection. A, lymphangiectasis with accumulation of lymphocytes in the central lymphatic vessel; B, PMNLs within the villus epithelium on the side attached to the inflamed PP. Haemalum. 


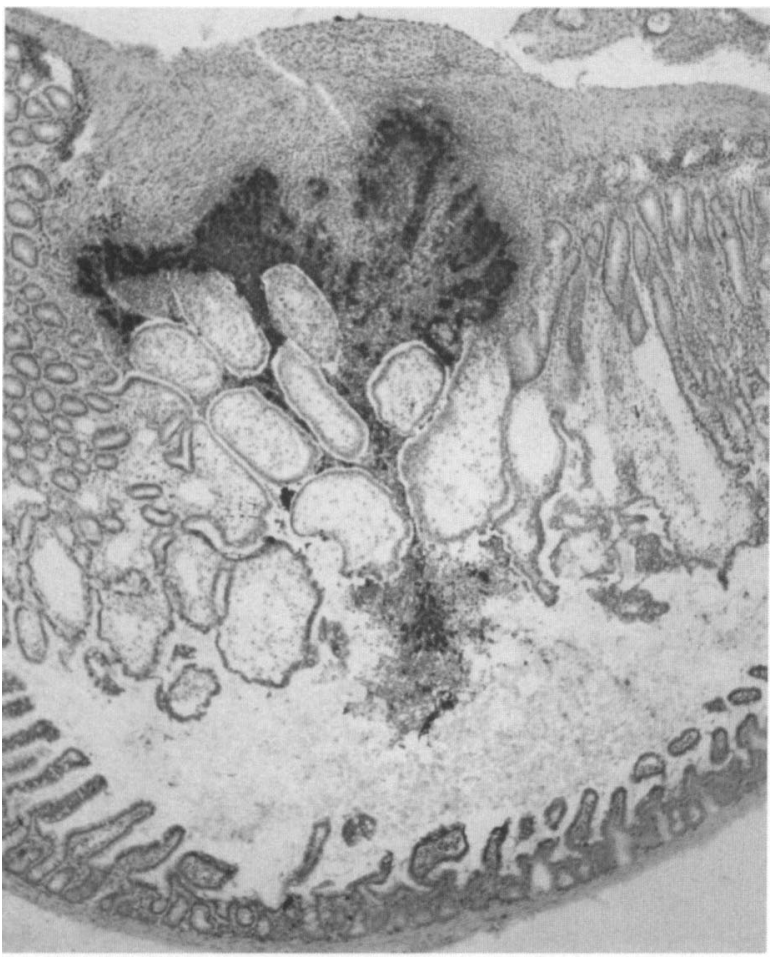

Fig. 9. Cryosection of PP destroyed by a yersinia-induced abscess 7 days after orogastric infection. Immunostaining (PAP-method, brown signal) with polyclonal anti-yersinia antibodies (WA-v). Haemalum counterstaining.

including enterocytes and $M$ cells could no longer be observed in infected PP.

\section{Dissemination of $Y$. enterocolitica from PP to other organs}

At 5 days after infection yersinia-induced abscesses in the mesenteric lymph nodes could be observed, suggesting that $Y$. enterocolitica disseminates via the lymphatic vessels. These abscesses resembled those found in the PP and comprised yersiniae and Mac- $1^{+}$ phagocytes (not shown). However, TEM studies on yersinia-infected PP of ligated ileal loops occasionally revealed $Y$. enterocolitica within venules as soon as $3 \mathrm{~h}$ after the infection (Fig. 11) suggesting that in addition to the lymphatic system $Y$. enterocolitica may disseminate via blood vessels from PP to other organs such as the spleen and liver.

\section{Discussion}

Peyer's patches (PP) are a part of the gut-associated lymphoid tissue (GALT) and consist of lymphoid follicles and a specialised epithelial cell layer called follicle-associated epithelium (FAE) [12]. Cells with shorter microvilli have been observed within the FAE and referred to as membranous, microfold or $M$ cells $[19,36]$. These cells are specialised in the way that they take up and deliver antigens from the lumen of the intestine to the lymphoid cells of the PP which are believed to represent the afferent limb of the GALT $[20,21,37]$. In that way immune responses against intestinal pathogens may be triggered and may result in production and secretion of $\operatorname{IgA}$ antibodies on to mucosal surfaces $[20,21,37,38]$.

$M$ cells have an extraordinary capacity for particle translocation $[39,40]$. However, whether the translocation via $\mathrm{M}$ cells is a non-specific mechanism or whether specific interactions and cellular signals are required for this process remains to be established.
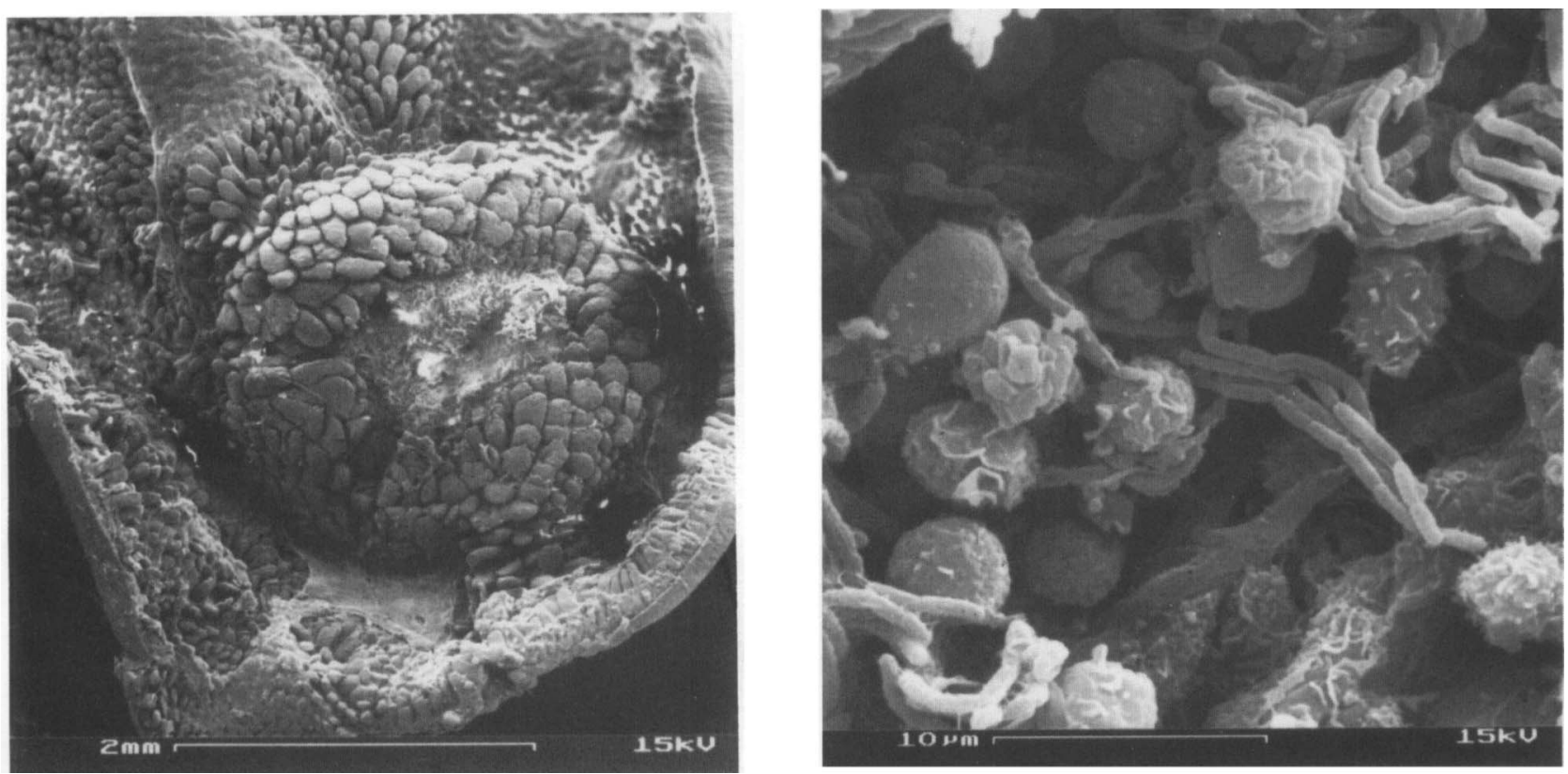

Fig. 10. SEM of PP 7 days after orogastric $Y$. enterocolitica infection. A, PP with enlarged adjacent villi destroyed dome $(\times 20)$; B, Chain-forming yersiniae and phagocytes on the surface of the destroyed FAE, $(\times 280)$. 


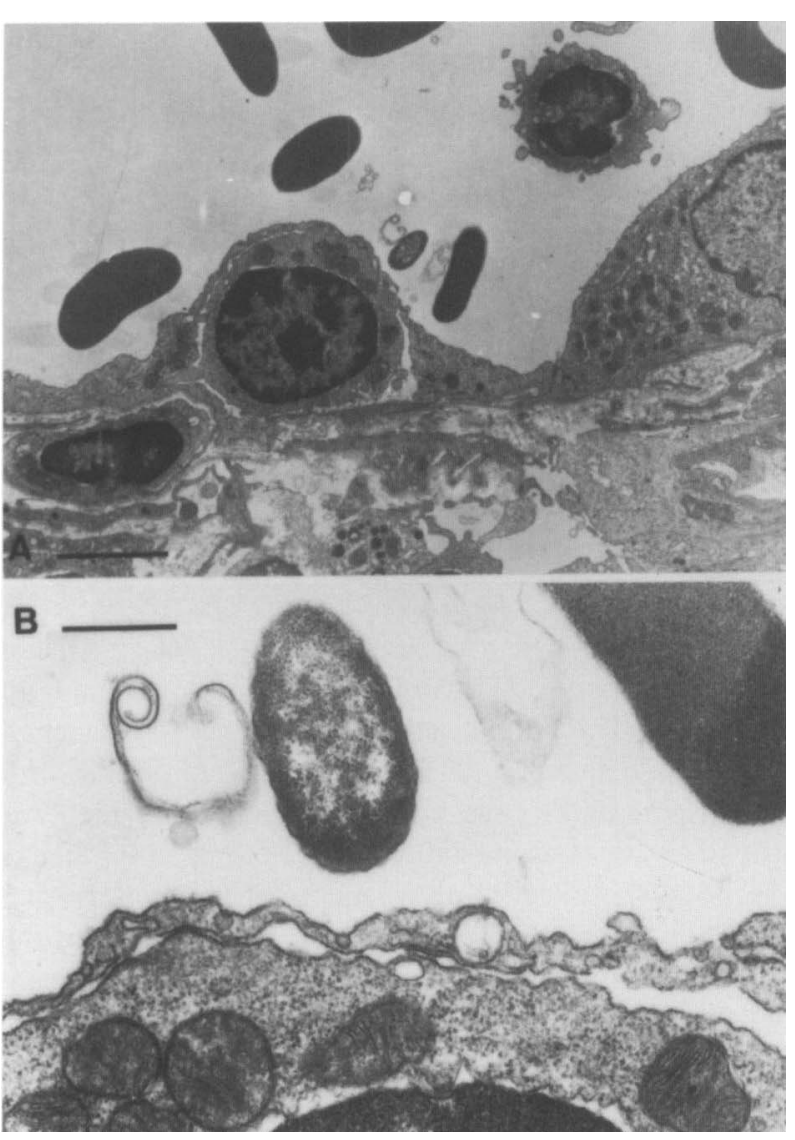

Fig. 11. TEM of a venule with $Y$. enterocolitica and erythrocytes from a PP $180 \mathrm{~min}$ after infection of an ileal loop. Bar: A, 6, B, $1 \mu \mathrm{m}$.

Many micro-organisms use $M$ cells to get access to host tissue and to establish an infection. Hence, not only have bacterial species such as Shigella, Salmonella, Vibrio and Listeria been demonstrated in association with $M$ cells but also viruses such as reovirus and HIV [20]. Once they have entered the PP via $\mathrm{M}$ cells, certain micro-organisms, e.g., S. typhimurium, induce destruction of $\mathrm{M}$ cells [25], or as in the case of $S$. flexneri, induce apoptosis of adjacent macrophages [29]. These processes probably depend on the expression of individual virulence factors and may be crucial for the subsequent infection process.

The aim of the present study was to elucidate the events in PP after intestinal $Y$. enterocolitica infection. For this purpose mice were infected orogastrically with $Y$. enterocolitica of serotype 08 ; or alternatively, ileal loop experiments were performed. Based on the results of the present study the following scenario of intestinal $Y$. enterocolitica infections can be proposed. $Y$. enterocolitica initially binds to cells of the FAE, including both enterocytes and $M$ cells, but not to the epithelium of the villi. However, Y. enterocolitica selectively invades $M$ cells but no other types of cells of the FAE. After invasion into PP tissues, yersiniae express the major outer-membrane protein YadA, which mediates resistance against phagocytosis; thus, they replicate extracellularly. This process is paralleled by recruitment of phagocytes and thereby formation of abscesses, which results in the destruction of FAE and PP tissues. Moreover, the present study revealed evidence that yersiniae may disseminate from the PP to spleen and liver via the lymphatics and possibly also via blood vessels.

The observations on the invasion mechanism of $Y$. enterocolitica presented herein support the results of previous studies $[17,18]$ and resemble the mechanism observed for other micro-organisms, suggesting that invasion of the intestinal wall by penetration of $M$ cells is a common feature shared by many enteroinvasive bacteria [21].

A recent report on experimental salmonellosis provided evidence that $S$. typhimurium selectively binds to, interacts with, and thereby induces ruffling of the membranes, of M cells of the FAE [25]. Then $S$. typhimurium invades and thereafter destroys the $M$ cells [25]. The latter probably depends on virulence factors of $S$. typhimurium because avirulent aro mutants even induce an increase of $M$ cell formation [41].

$Y$. enterocolitica was observed to bind to both enterocytes and $M$ cells of the FAE. Ruffling of membranes, as observed in salmonellosis [25, 42], was not found after $Y$. enterocolitica infection. Whether the vesicle-like structures that appeared 2 days after yersinia infection on the FAE are related structures and due to similar mechanisms remains to be elucidated. Moreover, destruction of the FAE was observed 2-4 days after infection although there was no direct evidence that $Y$. enterocolitica itself may induce killing of $M$ cells. Thus far it is not clear whether this destruction is due to a cytotoxic factor produced by $Y$. enterocolitica or whether the inflammatory host response may account for these tissue alterations. Hence, the destruction of the PP could be the result of the action of virulence factors of $Y$. enterocolitica such as YopE. This protein can be translocated into eukaryotic target cells and exerts cytotoxic activity by depolymerisation and disruption of actin microfilaments $[43,44]$. On the other hand, by $24 \mathrm{~h}$ after infection PMNL accumulate in yersiniainduced lesions immediately beneath the FAE. Moreover, PMNL were found within the epithelium of adjacent villi. These cells can produce toxic products, e.g., proteases and reactive oxygen metabolites $[45,46]$. The latter have been demonstrated to be released upon exposure to $Y$. enterocolitica [47]. Furthermore, cytotoxic $T$ cells have been shown to play a role during yersinia infection $[14,48]$. Thus, the action of both types of cells might induce tissue damage itself or might aggravate the tissue lesions induced by $Y$. enterocolitica.

In shigellosis the transmigration of PMNL is believed to aggravate the disease by opening paracellular 
pathways of entry [30]. Similar PMNL were found transmigrating within the epithelium of villi adjacent to infected PP and destruction of the FAE was observed which was paralleled by the recruitment of PMNL into the PP. Furthermore, S. flexneri is believed to multiply intracellularly and to spread from cell to cell after penetration via $\mathrm{M}$ cells [29]. In contrast, this study and others $[17,49,50]$ found that $Y$. enterocolitica is located extracellularly, and so far there is no evidence for cell-to-cell spread. Hence, Y. enterocolitica was found exclusively within $M$ cells but not within other cells such as enterocytes. However, it must be stressed that the ultrastructural and histological methods used herein allow the assessment of only very limited tissue samples, and the possibility of an additional invasion mechanism cannot be excluded.

Taken together, as observed for shigellae and salmonellae, $Y$. enterocolitica selectively invades the PP by penetration of $\mathrm{M}$ cells. However, immediately after the invasion of the PP these pathogens obviously exert distinct mechanisms to establish an infection. Shigellae-induced lesions are commonly limited to the mucosa and lamina propria [29] whereas salmonellae, after killing of $\mathrm{M}$ cells, may invade and replicate within phagocytes and lymphoid cells of the PP $[25,28]$. In contrast, after penetration of $M$ cells $Y$. enterocolitica replicates extracellularly and causes a destruction of the PP including FAE and rapidly disseminates into other organs. Currently the tissue alterations induced by different strains and mutants are being investigated in this laboratory to determine whether specific features of the pathogen itself or the inflammatory host reaction may account for this pathomechanism.

We thank J. Heesemann (Institut für Hygiene und Mikrobiologie, Würzburg) and G. Krohne (Abteilung Elektronenmikroskopie, Theodor-Boveri-Institut für Biowissenschaften, Würzburg) for discussions and critical review of the manuscript. This work was supported by a grant of the Bundesministerium für Forschung und Technologie.

\section{References}

1. Cover TL, Aber RC. Yersinia enterocolitica. $N$ Engl $J$ Med 1989; 321: 16-24.

2. Hoogkamp-Korstanje JAA, de Koning J, Samsom JP. Incidence of human infection with Yersinia enterocolitica serotypes O3, 08 , and $\mathrm{O} 9$ and the use of indirect immunofluorescence in diagnosis. J Infect Dis 1986; 153: 138-141.

3. Rabson AR, Hallett AF, Koornhof HJ. Generalized Yersinia enterocolitica infection. $J$ Infect Dis 1975; 131: 447-451.

4. Bouza E, Dominguez A, Meseguer $\mathrm{M}$ et al. Yersinia enterocolitica septicemia. Am J Clin Pathol 1980; 74: 404 409.

5. Ahvonen P, Sievers K, Aho K. Arthritis associated with Yersinia enterocolitica infection. Acta Rheumatol Scand 1969; 15: $232-253$.

6. Granfors $\mathrm{K}$, Viljanen M, Tiilikainen A, Toivanen A. Persistence of $\operatorname{IgM}, \operatorname{IgG}$, and $\operatorname{IgA}$ antibodies to Yersinia in yersinia arthritis. J Infect Dis 1980; 141: 424-429.

7. Carter PB. Animal model of human disease. Yersinia enteritis. Animal model: oral Yersinia enterocolitica infection of mice. Am J Pathol 1975; 81: 703-706.
8. Heesemann J, Gaede K, Autenrieth IB. Experimental Yersinia enterocolitica infection in rodents: a model for human yersiniosis. APMIS 1993; 101: 417-429.

9. Carter PB. Pathogenicity of Yersinia enterocolitica for mice. Infect Immun 1975; 11: 164-170.

10. Autenrieth IB, Hantschmann P, Heymer B, Heesemann J. Immunohistological characterization of the cellular immune response against Yersinia enterocolitica in mice: evidence for the involvement of T lymphocytes. Immunobiology 1993; 187: $1-16$.

11. Beuscher HU, Rausch U-P, Otterness IG, Röllinghoff M. Transition from interleukin 1 beta (IL-1 beta) to IL-1 alpha production during maturation of inflammatory macrophages in vivo. $J$ Exp Med 1992; 175: 1793-1797.

12. Pospischil A. [Structure and function of Peyer's patches in the intestines of different animal species.] Schweiz Arch Tierheilkd 1989; 131: 595-603.

13. Bienenstock $\mathrm{J}$, Befus $\mathrm{AD}$. Review: mucosal immunology. Immunology 1980; 41: 249-270.

14. Autenrieth IB, Tingle A, Reske-Kunz A, Heesemann J. T lymphocytes mediate protection against Yersinia enterocolitica in mice: characterization of murine T-cell clones specific for $Y$. enterocolitica. Infect Immun 1992; 60: 1140-1149.

15. Autenrieth IB, Vogel U, Preger S, Heymer B, Heesemann J. Experimental Yersinia enterocolitica infection in euthymic and T-cell-deficient athymic nude C57BL/6 mice: comparison of time course, histomorphology, and immune response. Infect Immun 1993; 61: 2585-2595.

16. Autenrieth IB, Beer M, Bohn E, Kaufmann SHE, Heesemann J. Immune responses to Yersinia enterocolitica in susceptible $\mathrm{BALB} / \mathrm{c}$ and resistant C57BL/6 mice: an essential role for gamma interferon. Infect Immun 1994; 62: 2590-2599.

17. Hanski C, Kutschka U, Schmoranzer HP et al. Immunohistochemical and electron microscopic study of interaction of Yersinia enterocolitica serotype 08 with intestinal mucosa during experimental enteritis. Infect Immun 1989; 57: 673-678.

18. Grützkau A, Hanski $\mathrm{C}$, Hahn $\mathrm{H}$, Riecken EO. Involvement of $M$ cells in the bacterial invasion of Peyer's patches: a common mechanism shared by Yersinia enterocolitica and other enteroinvasive bacteria. Gut 1990; 31: 1011-1015.

19. Bye WA, Allan CH, Trier JS. Structure, distribution, and origin of $M$ cells in Peyer's patches of mouse ileum. Gastroenterology 1984; 86: 789-801.

20. Neutra MR, Kraehenbuhl J-P. Transepithelial transport and mucosal defence I: the role of M cells. Trends Cell Biol 1992; 2: 134-138.

21. Giannasca PJ, Neutra MR. Interactions of microorganisms with intestinal $M$ cells: mucosal invasion and induction of secretory immunity. Infect Agents Dis 1994; 2: 242-248.

22. Miller VL, Falkow S. Evidence for two genetic loci in Yersinia enterocolitica that can promote invasion of epithelial cells. Infect Immun 1988; 56: 1242-1248.

23. Miller VL, Finlay BB, Falkow S. Factors essential for the penetration of mammalian cells by Yersinia. Curr Top Microbiol Immunol 1988; 138: 15-39.

24. Miller VL. Tissue-culture invasion: fact or artefact? Trends Microbiol 1995; 3: 69-71.

25. Jones BD, Ghori N, Falkow S. Salmonella typhimurium initiates murine infection by penetrating and destroying the specialized epithelial M cells of the Peyer's patches. J Exp Med 1994; 180: 15-23.

26. Kohbata S, Yokoyama H, Yabuuchi E. Cytopathogenic effect of Salmonella typhi GIFU 10007 on M cells of murine ileal Peyer's patches in ligated ileal loops: an ultrastructural study. Microbiol Immunol 1986; 30: 1225-1237.

27. Hsu HS. Pathogenesis and immunity in murine salmonellosis. Microbiol Rev 1989; 53: 390-409.

28. Finlay BB. Molecular and cellular mechanisms of Salmonella pathogenesis. Curr Top Microbiol Immunol 1994; 192: 163185.

29. Sansonetti PJ. Molecular mechanisms of cell and tissue invasion by Shigella flexneri. Infect Agents Dis 1993; 2: 201-206.

30. Perdomo JJ, Gounon P, Sansonetti PJ. Polymorphonuclear leukocytes transmigration promotes invasion of colonic epithelial monolayer by Shigella flexneri. J Clin Invest 1994; 93: 633-643.

31. Heesemann J, Laufs R. Construction of a mobilizable Yersinia enterocolitica virulence plasmid. J Bacteriol 1983; 155: 761-767. 
32. Vogel U, Autenrieth IB, Berner R, Heesemann J. Role of plasmid-encoded antigens of Yersinia enterocolitica in humoral immunity against secondary $Y$. enterocolitica infection in mice. Microb Pathog 1993; 15: 23-36.

33. Karnovsky MJ. A formaldehyde-glutaraldehyde fixative of high osmolality for use in electron microscopy. $J$ Cell Biol 1965; 27: 137 A (Abstract).

34. Davis CP, Savage DC. Habitat, succession, attachment, and morphology of segmented, filamentous microbes indigenous to the murine gastrointestinal tract. Infect Immun 1974; 10: 948-956.

35. Klaasen HLBM, Koopman JP, Poelma FGJ, Beynen AC. Intestinal, segmented, filamentous bacteria. FEMS Microbiol Rev 1992; 88: 165-180.

36. Owen RL, Jones AL. Epithelial cell specialization within human Peyer's patches: an ultrastructural study of intestinal lymphoid follicles. Gastroenterology 1974; 66: 189-203.

37. Staats HF, Jackson RJ, Marinaro M, Takahashi I, Kiyono $H$, McGhee JR. Mucosal immunity to infection with implications for vaccine development. Curr Opin Immunol 1994; 6: 572-583.

38. Kraehenbuhl J-P, Neutra MR. Transepithelial transport and mucosal defence II. secretion of IgA. Trends Cell Biol 1992; 2: $170-174$.

39. Neutra MR, Phillips TL, Mayer EL, Fishkind DJ. Transport of membrane-bound macromolecules by $M$ cells in follicleassociated epithelium of rabbit Peyer's patch. Cell Tissue Res 1987; 247: 537-546.

40. Pappo J, Ermak TH. Uptake and translocation of fluorescent latex particles by rabbit Peyer's patches follicle epithelium: a quantitative model for M cell uptake. Clin Exp Immunol 1989; 76: $144-148$.

41. Savidge TC, Smith MW, James PS, Aldred P. Salmonellainduced M-cell formation in germ-free mouse Peyer's patch tissue. Am J Pathol 1991; 139: 177-184.
42. Francis CL, Ryan TA, Jones BD, Smith SJ, Falkow S. Ruffles induced by Salmonella and other stimuli direct macropinocytosis of bacteria. Nature 1993; 364: 639-642.

43. Rosqvist $\mathrm{R}$, Magnusson K-E, Wolf-Watz $\mathrm{H}$. Target cell contact triggers expression and polarized transfer of Yersinia YopE cytotoxin into mammalian cells. EMBO $J$ 1994; 13: 964-972.

44. Rosqvist R, Forsberg A, Wolf Watz H. Microinjection of the Yersinia YopE cytotoxin in mammalian cells induces actin microfilament disruption. Biochem Soc Trans 1991; 19: 1131-1132

45. Klebanoff SJ. Phagocytic cells: products of oxygen metabolism. In: Gallin JI, Goldstein IM, Snyderman R (eds) Inflammation: basic principles and clinical correlates. New York, Raven-Press Ltd. 1988: 391-444.

46. Henson PM, Henson JE, Fittschen C, Kimani G, Bratton DL, Riches DWH. Phagocytic cells: degranulation and secretion. In: Gallin JI, Goldstein IM, Snyderman R (eds) Inflammation: basic principles and clinical correlates. New York, Raven Press. 1988: 363-390.

47. Ewald JH, Heesemann J, Rüdiger H, Autenrieth IB. Interaction of polymorphonuclear leukocytes with Yersinia enterocolitica: role of the Yersinia virulence plasmid and modulation by the iron-chelator desferrioxamine B. J Infect Dis 1994; 170: 140-150.

48. Starnbach MN, Bevan MJ. Cells infected with Yersinia present an epitope to class I MHC-restricted CTL. J Immunol 1994; 153: $1603-1612$.

49. Lian C-J, Hwang WS, Pai CH. Plasmid-mediated resistance to phagocytosis in Yersinia enterocolitica. Infect Immun 1987; 55: 1176-1183.

50. Hessemann J, Grüter L. Genetic evidence that the outer membrane protein Yopl of Yersinia enterocolitica mediates adherence and phagocytosis resistance to human epithelial cells. FEMS Microbiol Lett 1987; 40: 37-41. 